www.uoc.edu

\title{
Exploring the information space: a strategic perspective on information systems
}

Max Boisot (boisot@attglobal.net)

Researcher (IN3-UOC)

Sol Snider Center for Entrepreneurial Research (The Wharton School, University of Pennsylvania)

Submission date: January 2004

Published in: May 2004

Internet Interdisciplinary Institute (IN3): http://www.uoc.edu/in3/eng/index.htm 
Thinking on information systems has tended to conflate data, information and knowledge. Intelligent agents convert data into information and thence into knowledge through a two-step filtering process that is guided by the possession of prior knowledge. Agents, however, have finite brains and intelligence, and often encounter more data and information than they can process or store. To deal with the problem of overload, they have recourse to external processing and storage devices - ie, artefacts or 'external scaffolding' of various kinds - to overcome this problem. Networks of such artefacts, in effect, make up embryonic information systems that have the agent at their centre. Due to the ever-increasing technical change, the division of labour is constantly shifting, both between the external scaffolding and the agent using it or within the agent itself, between embodied, narrative, and abstract forms of knowledge. What determines this shift?

In the paper we show that the way in which information is structured affects how it flows within a group of agents - a family, organization or wider society - and whether it gets embedded in physical or institutional scaffolds or agents. Information and communication technologies aim to facilitate the structuring of information and hence its flow. These technologies, thus, materially modify the information environment within which an agent, or group of agents, acts and interacts. We shall argue that the agenda for the future development of information systems needs to broaden out to encompass a wider conception of its mission, one that relates an agent's, or group of agents', learning needs to the nature of the information environment that they face. We present a conceptual framework, the Information Space or I-Space, which will help us address the issue. We then apply the framework to the question posed above.

Information systems, knowledge management, organizational learning, information flows

\section{SUMMARY}

1. Introduction

2. The I-Space

3. The I-Space applied to IS

4. Conclusion

References

To cite this document, you could use the following reference:

BOISOT, Max (2004). Exploring the information space: a strategic perspective on information systems [Online Working Paper]. IN3-UOC: (Working Paper Series; WP04-003) [Date of citation: dd/mm/yy]

<http://www.uoc.edu/in3/dt/20415/index.html> 


\title{
Exploring the Information Space: A Strategic Perspective on $\underline{\text { Information Systems }^{1}}$
}

\author{
Max Boisot \\ Universitat Oberta de Catalunya \\ and \\ The Sol Snider Center, The Wharton School
}

\section{Introduction}

We can think about information systems in two ways. Firstly, we can think of them normatively, that is, as organizational supports. They then tend to be defined in terms of organizational tasks and draw on a functionalist perspective characteristic of the engineer. This perspective, focused on technology, the computer, and well-defined input/output relationships, systems, customers, users, etc., has been the one that has traditionally characterized. It is the practitioner perspective. A second, alternative approach is to take an information system as a description of the way that information flows in and around different types of system. In this second approach the body has an information system hormonal and/or nervous - and so does a city or an economic organization (Checkland

\footnotetext{
${ }^{1}$ To be published in D. Rooney, G. Hearn, and A. Ninan (Editors), The Knowledge Economy Handbook, Edward Elgar Publishing. The author wishes to thank Agusti Canals and Ramon O'Callaghan for their useful comments and suggestions on earlier drafts of this paper.
} 
and Howell,1998). This second perspective on information systems often operates at a higher level of abstraction than the first (Clarke, 2001). Here, we adopt features of the second perspective to modify certain features of the first. We look at how the way that the information flows in and around systems affects the nature of the information processing tasks that make up the IS function within organizations and the kinds of knowledge that can be generated from these.

Whether they are viewed normatively or descriptively, as has been the case with many other information-related intellectual disciplines, thinking on information systems has tended to conflate, data, information and knowledge (McRae, 1971; Boisot and Canals, 2004). Strictly speaking, the raw material of any Information System is data, that is, discernable differences between physical states of the world that get registered as such for some agent or agency. Data is always borne on some physical substrate, whether it be stone, paper, or pure electromagnetic waves. The challenge then becomes to extract information - recurrent regularities that can give rise to expectations - from the data through some definable operation. A computer program, for example, is typically designed to do just that and if it is successful, the program's output data will then be more information-rich than its input data. But information has to be converted into knowledge if it is to have any effect at all. Like the pragmatists and the evolutionary epistemologists, we are inclined to associate knowledge more with a disposition to action than with the disinterested pursuit of truth, that is, we are more aligned with Pierce, James, and Campbell, than with Plato (Pierce, 1868; James, 2000; Campbell, 1974). Although these two views of knowledge are not actually incompatible (Boisot and MacMillan, 
forthcoming), the focus here is thus on the value of knowledge to an action system such as a living organism rather than on abstract truth conditions that need to be met in order to achieve a given level of certainty.

Intelligent agents convert data into information and thence into knowledge through a twostep filtering process that is guided by the possession of prior knowledge. In the first step, noise is filtered out from incoming signals by the agent's sensory apparatus and the latter gets registered as data by different senses. In the second, non-information bearing data gets filtered out by the agent's conceptual apparatus, so that only information bearing data is left to impact its action system and thus get metabolised into knowledge. Figure 1 is an adaptation of Newell, Shaw, and Simon's model of information processing that illustrates the process (McRae, 1971). As indicated in the diagram, the perceptual and conceptual filters are activated by the agent's prior knowledge and experience.

(Place Figure 1 here)

Agents have finite brains and intelligence. They often encounter more data and information than they can process or store. How do they deal with the resulting overload without blowing a fuse? They have recourse to external processing and storage devices ie, artefacts of various kinds - to overcome the problem. Stewart and Cohen call this use of external props extelligence, Gregory calls it potential intelligence, and Andy Clark calls it external scaffolding (Stewart and Cohen, 1997; Gregory, 1981; Clark, 1997). Networks of such artefacts, in effect, make up embryonic information systems that have 
the agent at their centre. Take, for example a kitchen. The layout of a kitchen articulates a kind of 'script' with much information embedded in the physical form of the kitchen layout, in the equipment, and in the utensils to be found there (Schank and Abelson, 1997). A well-designed kitchen communicates relevant information to its user and minimizes his or her search time: cutlery is likely to be found in drawers, pots and pans in the deeper cupboards, the hot water tap above the kitchen sink, and so on. There is one code for dealing with cookers, another one for dealing with refrigerators and a third for dishwashing machines. These codes are often set out in the manufacturers' instruction booklet. Note, however, that such information only registers with someone having a prior familiarity with kitchens and thus having some knowledge of the design codes that are being used.

In sum, a kitchen can be considered an information system whose major components are embedded and distributed in artefacts. It was not explicitly designed as an information system, however, so that here we are using the term descriptively rather than normatively. The path-dependent design conventions that shaped the evolution of the kitchen as an information system, incrementally 'decided' what information to embed in the external scaffolding - ie, the kitchen and equipment design - and what prior knowledge to require of the kitchen user. A process of natural selection operating on numberless small design decisions established the best division of labour between the different elements of the information system, those that are external and those that are internal the user. 
A kitchen constitutes a physical piece of external scaffolding. But external scaffolding can also take the form of social institutions, organizations and conventions (Checkland and Howell, 1998). In either case, with ever-increasing technical change, the division of labour is constantly shifting, both between the external scaffolding and the agent using it, and also within the agent, between embodied, narrative, and abstract forms of knowledge. What determines the shift?

Such a question takes us well upstream of the functionalist view of information systems with its narrow focus on immediately given organizational tasks. Answering it requires some understanding of how information evolves as it flows within and across intelligent agents or action systems at the most general level. In what follows we show that how information is structured affects how it flows within a group of agents - a family, an organization, or a larger society - and whether it gets embedded in physical or institutional scaffolds or in agents. Information and communication technologies aim to facilitate the structuring of information and hence its flow. These technologies thus materially modify the information environment within which an agent, or a group of agents, act and interact. We shall argue that the agenda for the future development of information systems needs to broaden out to encompass a wider conception of its mission, one that relates an agent's, or a group of agents' learning needs to the nature of the information environment that respectively confront them. In the next section, 2, we present a conceptual framework, the Information Space or I-Space, which will help us address the issue. We then apply the framework to the question in Section 3 and offer a brief conclusion in section 4 . 


\section{The I-Space}

The I-Space builds on the proposition that the structuring of data facilitates its diffusion (Boisot, 1995; 1998). The structuring of data, the process through which information is extracted from data, is achieved through acts of codification and abstraction

Codification draws distinctions and articulates boundaries between states or around objects. Codification is a precondition for the creation of objects and categories. It will be harder to codify fuzzy boundaries or objects than those that are well formed; the amount of data processing required to do so will be greater.

Abstraction treats things that are different as if they were the same (Dretske, 1981). It either associates or - if they are recurrent - correlates the objects or categories discerned or created by codification and allows one object or category to stand in for another, thus reducing the number of these that one needs for navigating in particular situations. As with codification, the amount of data processing required to perform an abstraction will be greater when objects or categories are only weakly correlated with each other than when they are strongly so.

Codification and abstraction are matters of degree. We can represent them as the two dimensions of an Epistemological Space of E-Space as indicated in Figure 2 (Boisot, 
1995). The vertical axis measures the ease with which the data of experience can be codified. At the top of the scale, little data processing will be required to distinguish between objects and categories, whereas at the bottom of the scale, are large amount and possibly an infinite amount - of data processing with be required. We can apply the same data processing measures to the act of abstracting. Towards the left of the abstraction scale, we encounter the world of concrete experience, one in which a large number of potential categories present themselves. Here a large amount of data processing - and, again, possibly an infinite amount - will be required to establish a correlation between categories. Towards the right, we are dealing with relatively few categories so that less data processing will be called for ${ }^{2}$.

(Place Figure 2 here)

The E-Space of Figure 2 allows us to identify three types of knowledge as a function of their degree of codification and abstraction: embodied knowledge, narrative knowledge, and formal knowledge. Embodied knowledge is rooted in behaviours and experiences that are largely tacit in nature (Polanyi, 1958) - playing tennis, riding a bicycle, etc. Although this kind of knowledge can be referred to, most of it cannot be articulated or placed into categories. Narrative knowledge can be thought of as an emanation of embodied knowledge. It covers those aspects of experience and behaviour that can be articulated into identifiable - though not always distinct - categories and hence, to some extent, shared with others. Whether because of a lack of coherence or a lack of

\footnotetext{
${ }^{2}$ We are here applying Chaitin's concept of Algorithmic Information Complexity (AIC) to the measurement of both codification and abstraction (Chaitin 1974).
} 
recurrence, however, narrative knowledge is typically not systematic enough to allow for its formalization. Formal knowledge, in turn, arises out of narrative knowledge and is the product of either logical or recurrent associations that have been both established between categories and stabilized enough for correlations to emerge. These facilitate abstraction.

Intelligent agents with finite capacities will be concerned to economize on their scarce data processing resources (Deacon, 1997). Moves towards greater codification and abstraction help them to achieve data processing economies. Codification and abstraction work in tandem and, over time, selectively shift limited quantities of embodied knowledge into a narrative mode. They subsequently allow a subset of such narrative to get formalized and to thereby acquire an abstract representation. The moves towards ever-higher levels of codification and abstraction can also be made to work in reverse. Abstract representations - universals, etc - find their way back into narrative discourse and help to shape it. Narratives leavened by abstractions in turn give coherence and meaning to tacit experiences that would otherwise remain uninterpreted and perhaps even undetected. This process has been well described by Deacon in his book The Symbolic Species (Deacon, 1997).

Note that abstract representations will travel further and faster within a population than ‘situated' narratives whose particular meanings are anchored to time and place. They can only do so, however, by sacrificing the richness and nuance of context. Note also, by contrast, that embodied knowledge hardly travels at all, for the most part being confined to the context in which it arises. Thus whereas embodied and narrative knowledge gives 
rise to highly personalized and rich interactions between agents that relate to each other primarily face-to-face, abstract knowledge gives rise to an impersonal order in which interacting agents may never actually meet.

We illustrate the relationship between codification, abstraction and diffusion by means of a curve as indicated in Figure 3. The figure - labelled an Information Space or I-Space is just an E-Space augmented by a diffusion dimension that allows us to locate a given population of intelligent agents along a scale. Towards the origin only a small percentage of agents have access to a given item of information or knowledge. At the end of the scale, close to $100 \%$ of the agent population will have access to a given item of information. What the curve tells us is that more agents can be reached in a given time period by codified and abstract knowledge than by uncodified and concrete knowledge. The diffusion curve constitutes half of a social learning cycle or SLC in which abstract representations are first extracted from narrative and embodied forms of knowledge and then subsequently work their way back into new narratives which then, in turn, help to shape tacit and embodied forms of knowledge that remains situated and undiffused. An SLC thus generates and subsequently integrates embodied, narrative and abstract forms of knowledge as indicated in Figure 4. Many different shapes of SLC are possible within an I-Space, signalling either the presence of blockages or catalysts to the flow of knowledge.

(Place Figures 3 and 4 here) 
What might these blockages or catalysts look like? Information and knowledge move through the space either through the cognitive efforts of individual agents or through a process of social exchange or transactions between agents. Both activities are either facilitated or hindered by the presence of institutional structures designed to lower data processing and transmission costs in a given region of the information environment captured by the I-Space. We identify four of these - markets, bureaucracies, clans, and fiefs - in Figure 5 and briefly summarize some of the information and cultural characteristics of these transactional structures in Table 1.

(Place Figure 5 and Table 1 here)

How might the emergence of new information and communication technologies (ICTs) affect the flows of information and knowledge in the I-Space? Could they affect the evolution of institutional structures? The new ICTs increase data processing and data transmission capacity of agents located along the diffusion dimension. At whatever level of codification or abstraction an agent operates, he or she can reach more agents with more data in a given time period than hitherto. We can think of this as a shift to the right of the diffusion curve of Figure 3 in the I-Space. Whether this data is information bearing, whether it then gets internalised by receiving agents and then converted into knowledge, is another matter, one that concerns the behaviour of agents with respect to the SLC as a whole. 
Figure 6 identifies two quite different effects of a rightward shift in the diffusion curve. The first is indicated by the arrow labelled A, that is parallel to the diffusion axis; it is the one that we can intuitively grasp since all it is telling us is that for a given level of codification and abstraction, a larger population can be reached with the new ICTs than with the old ones. The second effect, indicated by the downward pointing arrow, B, parallel to the codification axis, is less intuitively obvious. Arrow B tells us that for whatever size of population that one is trying to reach with a message, this can now be done at a lower level of codification and abstraction than hitherto.

(Place Figure 6 here)

The implication of this second effect is that messages have a much wider bandwidth available for their transmission than hitherto and that much of the richness and context of face-to-face communication might now be restored between parties even if these are transacting at some distance from each other. Pictures, videoconferencing, and Internet telephony will, by degrees, either replace or complement written text and numbers. In this way, the new ICTs will infuse a degree of personalization to distant communications ${ }^{3}$ by restoring to these the embodied and narrative components that were lost in the move towards greater codification and abstraction.

\section{The I-Space applied to IS}

\footnotetext{
${ }^{3}$ Note that in contrast to Evans and Wurster, we do not argue that the trade-off between 'richness' and 'reach' has been abolished by the new ICTs; it has merely been attenuated (Evans and Wurster, 2000).
} 
We are now in a position to address the question that we posed at the end of section 1 , namely, what is an appropriate division of labour between information systems that are internal to agents and those that are external to them? The question builds on a more basic one: what is an appropriate division of labour between embodied, narrative, and abstract forms of knowledge given the shape and flow dynamics of a given SLC and the constraints imposed by a given configuration of institutional structures in the I-Space? How might such a division of labour evolve over time and what should be IS' contribution to that evolution?

IS has its origins in the disciplines of accounting, management science, and decision sciences (Anthony, 1964; Scott Morton, 1991; Galbraith, 1973), all disciplines that exhibit a strong bias in favour of codification and abstraction. The bias was to confine many practitioners' conception of the IS mission to a very specific region of the I-Space, one which favoured an impersonal abstract order as well as technological solutions to the problem of generating and regulating information flows. Practitioners of the new discipline of knowledge management today inherit this bias - and find themselves limited by it $^{4}$. Other disciplines - ergonomics, human-computer interaction, etc - focus on the region of the I-Space which give rise to the kind of embodied knowledge that makes for good kitchen design. The intermediate region, the one inhabited by narrative knowledge, has also been attracting attention of late ${ }^{5}$.

\footnotetext{
${ }^{4}$ The emphasis here is on practitioners, most of whom come out of the IT stable. Academics in knowledge management such as Nonaka and Takeuchi have a more balanced view of knowledge management (Nonaka and Takeuchi, 1994).

${ }^{5}$ IBM's newly created Cynefin Centre for the Study of Organizational Complexity, for example, takes a focus on narrative knowledge as its point of departure
} 
No one discipline covers the SLC as a whole and none of the ones just cited talk much to each other. The result is a lack of integration across the different stages of the SLC. One discipline that is well placed to address the challenge of integration turns out to be IS, but to do so effectively, IS would have to come to terms with and manage the whole of the information environment as defined by the I-Space and not just the limited region it currently occupies. From this perspective, there is thus no need to choose between a technological and a humanist view of IS, as has been suggested by certain authors such as Clarke (Clarke, 2001), with each view located in a different region of the I-Space. The need is to recognize which view is appropriate to what circumstances and then to reconcile them. Such a contingency approach to IS would entail shifting the emphasis from an almost exclusive concern with static efficiency - a traditional focus of the discipline as it came to be constituted - to accommodate more dynamic issues of effectiveness and of learning. The new ICTs are now making this increasingly possible.

An effective IS system would aim to develop an integrated approach to managing the metamorphosis of data from embodied to narrative forms and thence to abstract forms of representation - and back again. In other words, it would take the management and development of an organization's or a community's learning processes - ie, its SLCs - as its prime mission. Such an approach would require the answers to three questions:

- What kind of knowledge are we dealing with and where is it located in the ISpace? How does it blend embodied, narrative, and abstract forms of 
representation? These questions could be answered by mapping an organization's or a community’s critical knowledge assets in the I-Space (Boisot, 1998)

- What phase of the learning cycle are we dealing with? The question could be answered by mapping an organization's or a community's critical SLCs in the ISpace.

- What institutional and cultural processes are acting to support or impede their operation? The question could be answered my mapping an organization's or a community's institutional and cultural structures in the I-Space

IS' core competence would then consist of integrating and then interpreting in a costeffective way the maps so created. If successful the exercise would result in the adaptation of ICTs to an organization's or a community’s learning processes instead of having things of the other way round as so often happens today.

\section{Conclusion}

In this paper, we have presented a conceptual model, the I-Space, that would help us to study information and knowledge flows as well as the different information environments that such flows give rise to. Our analysis turns out to constitute something of a challenge to the IS community. 
By asking questions that typically lie upstream of conventional IS concerns, this paper has argued for a significant broadening of the IS agenda to incorporate forms of knowledge - embodied, narrative - that it has hitherto tended to underplay or ignore, and to pay more attention to how, with learning, one form of knowledge evolves into the other. The proposed approach does not invalidate the discipline's current practices; nor does it render its current skills base obsolete. But by going beyond what might today be covered by the term 'Information system', it suggests a re-think of the IS mission.

The argument in favour of a re-think is becoming compelling. With the development of ambient computing, for example - the distribution of computational capacity to everyday artefacts - ICT's are bursting their banks, spilling out of the boxes to which they have hitherto been confined by computing pre-conceptions, and spreading out to occupy every nook and cranny of our environment. As a result, much embodied and narrative knowledge is now slowly becoming 'computable'. If IS remains locked in its computing era paradigms, then it will miss the opportunities that are currently opening up all around it to re-define itself.

\section{References}

Anthony, R., (1964) Management Accounting: Text and Cases, Homewood, Illinois: Richard D. Irwin Inc.

Blumenthal, S., (1969) Management Information Systems: A Framework for Planning and Development, Englewood Cliffs: Prentice Hall.

Boisot, M., (1995) Information Space: A Framework for Learning in Organizations, Institutions and Culture, London: Routledge 
Boisot, M., (1998) Knowledge Assets. Securing Competitive Advantage in the Information Economy Oxford University Press

Boisot, M. and Canals, A., (2004) 'Data, Information, and Knowledge: Have we Got it Right?' Journal of Evolutionary Economics, 14:1-25

Boisot, M., and MacMillan, I., (2003) 'Crossing Epistemological Boundaries: Managerial and Entrepreneurial Approaches to Knowledge’ Unpublished Manuscript

Campbell, D., (1974) ‘Evolutionary Epistemology’ in P.A. Schlipp (Ed.) The Philosophy of Karl Popper, La Salle, Illinois: Open Court Publishing

Chaitin, G. J.,(1974)"Information-Theoretic Computational Complexity" IEEE Transactions, Information Theory 20, 10

Checkland, P., and Howell, S., (1998) Information, Systems, and Information Sytems, Chichester, Sussex: John Wiley.

Clark, A., (1997) Being there: Putting Brain, Body, and World Together Again

Cambridge, MA, The MIT Press

Clarke, S., (2001) Information Systems Strategic Management: An Integrated Approach, London, Routledge

Deacon, T.W. 1997 The Symbolic Species, New York, Norton and Co.

Dretske, F., (1981) Knowledge and the Flow of Information, Cambridge, MA: MIT Press

Evans, P. and Wurster, T., (2000) Blown to Bits, Boston: Harvard Business School Press

Gregory, R.L., (1981) Mind in Science: A History of Explanations in Psychology and Physics, Middlesex, England: Penguin Books

James, W., (2000), Pragmatism (1907), New York: Penguin Books

McRae, T.W. (ed)1971. Management Information Systems Harmondsworth, Penguin Books

Pierce, C.S., (1868) "Questions Concerning Certain Faculties Claimed for Man", Journal of Speculative Philosophy Vol. 2, pp. 103-114

Polanyi, M., (1958) Personal Knowledge: Towards a Post-Critical Philosophy, London:

Routledge and Kegan Paul

Schank, R. and Abelson, R. 1997. Scripts, plans and knowledge. In Thinking: Readings in 
Cognitive Science, P. Johnson-Laird and P. Wason, eds. Cambridge University Press.

Scott Morton, M. (ed), (1991) The Corporation of the 1990s: Information Technology and Organizational Transformation, New York: Oxford University Press

Stewart, I. And Cohen, J., (1997) Figments of Reality: The Evolution of the Curious Mind : Cambridge University Press 


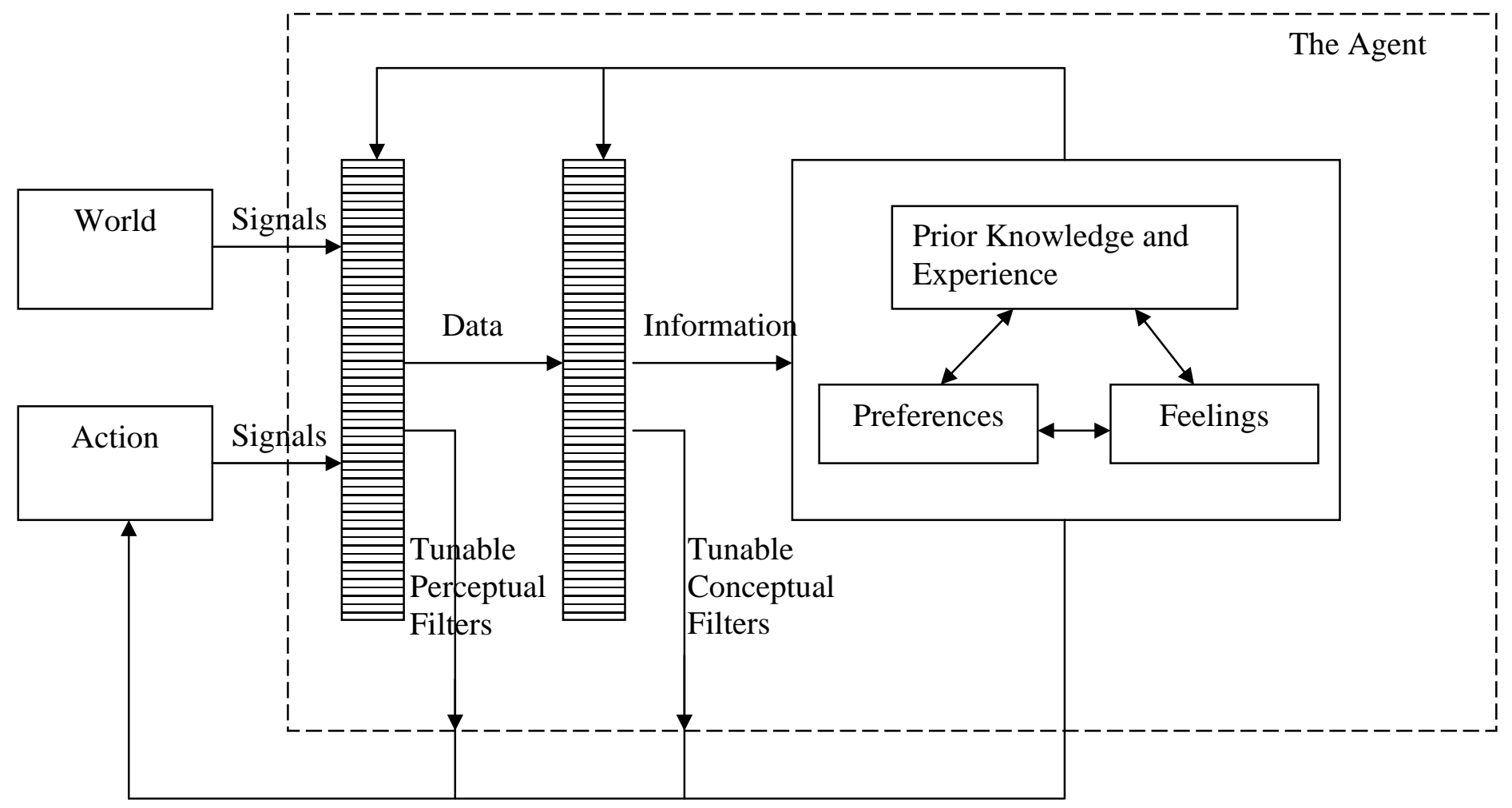

Figure 1: The agent and the world 


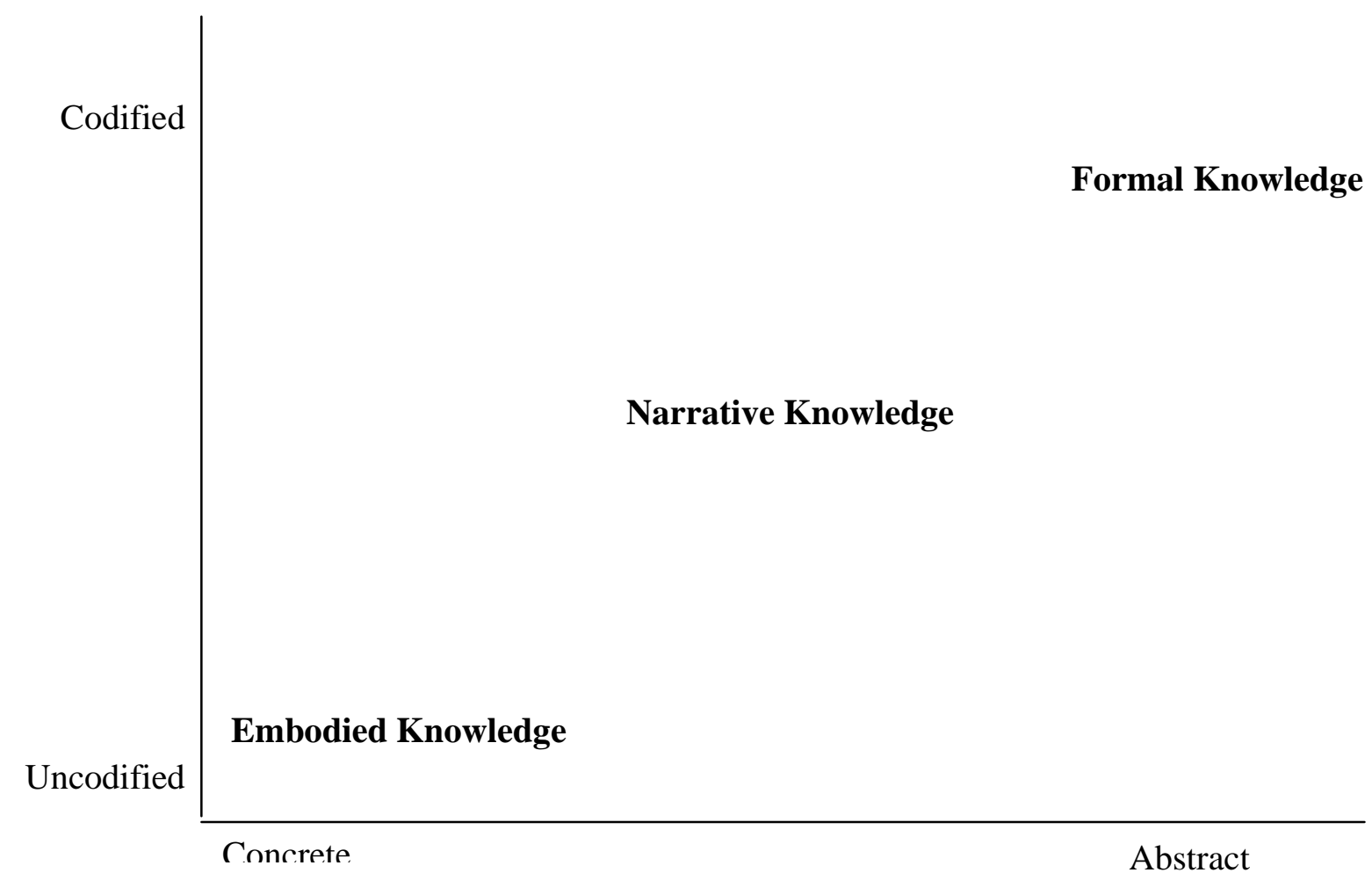

Figure 2: The E-Space 


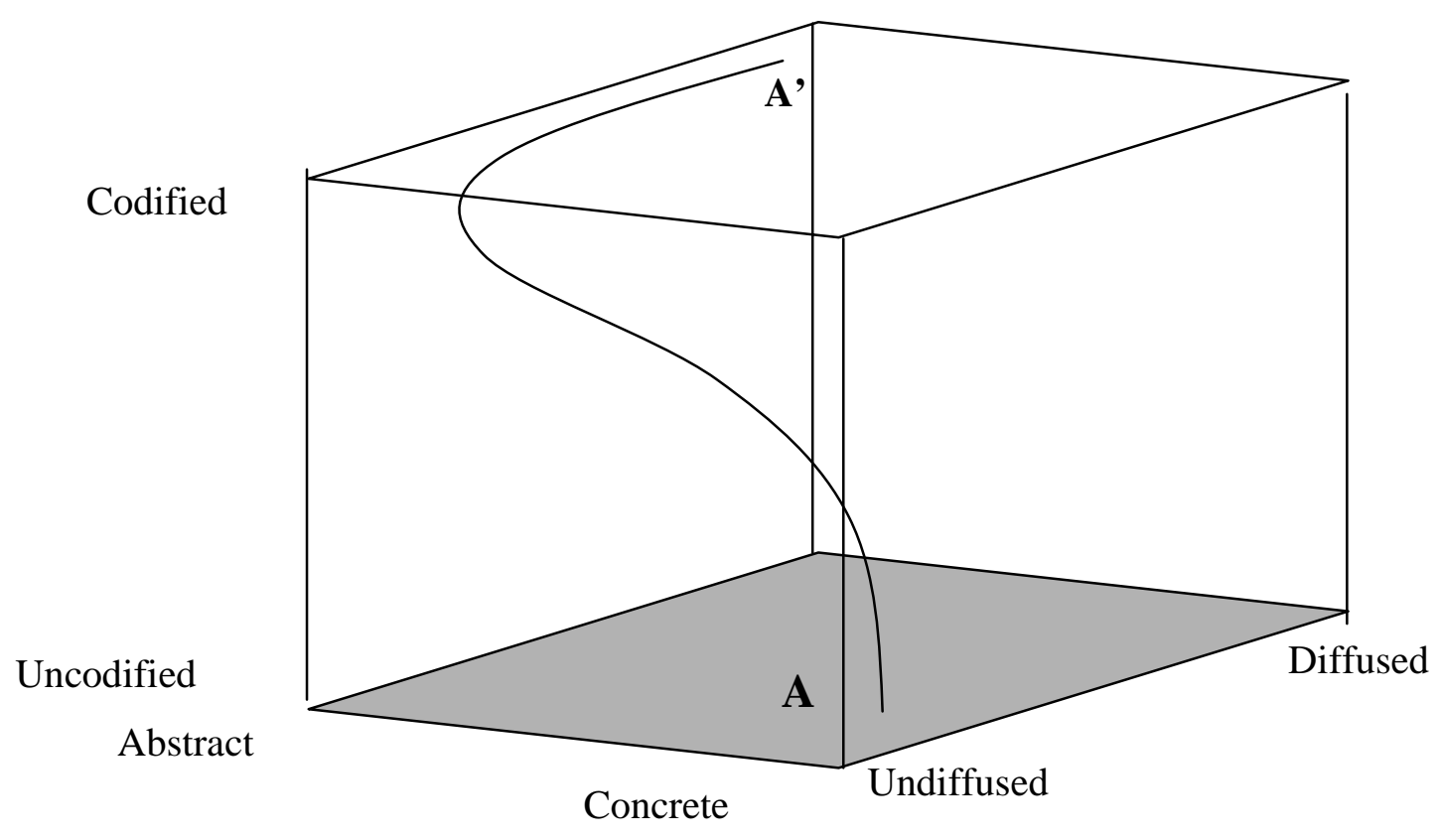

Figure 3: The I-

Space 


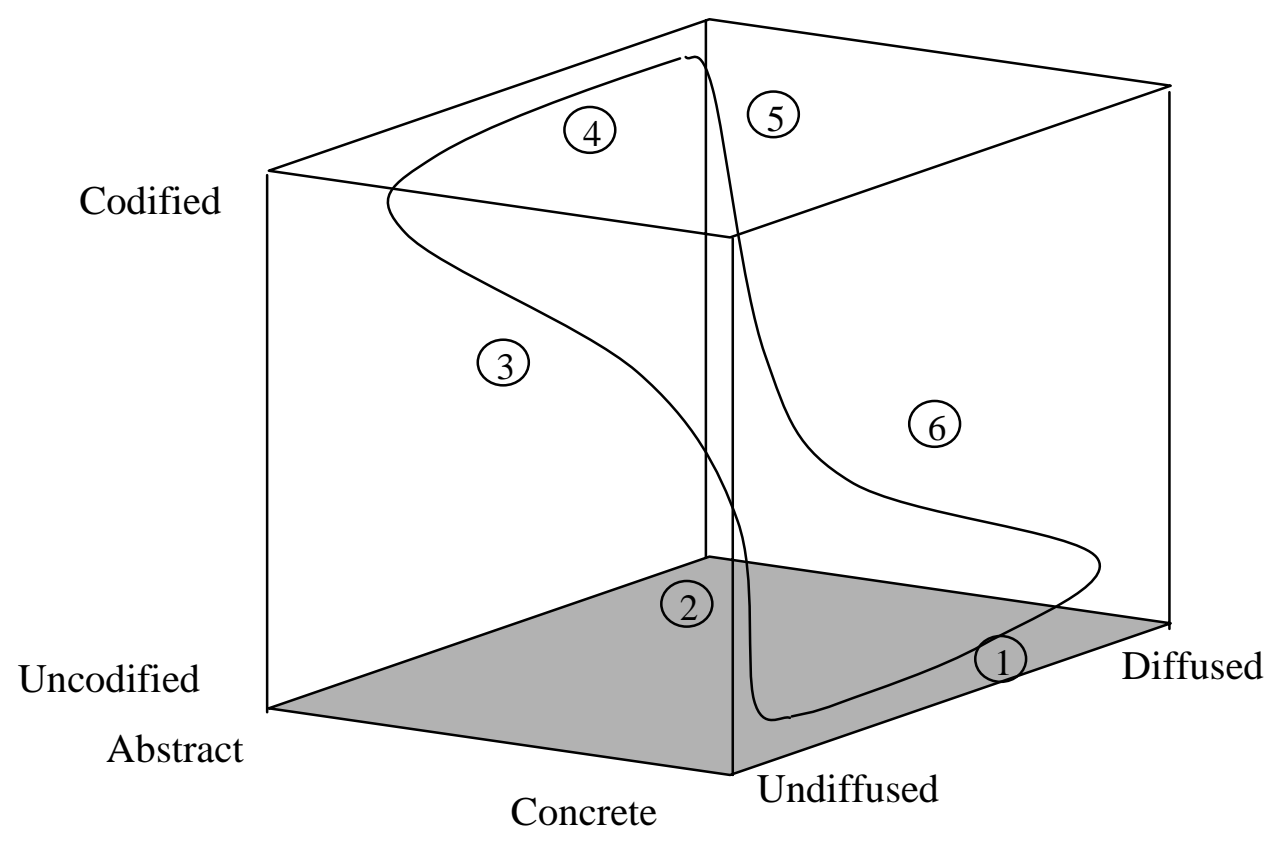

Figure 4: The Social Learning Cycle 


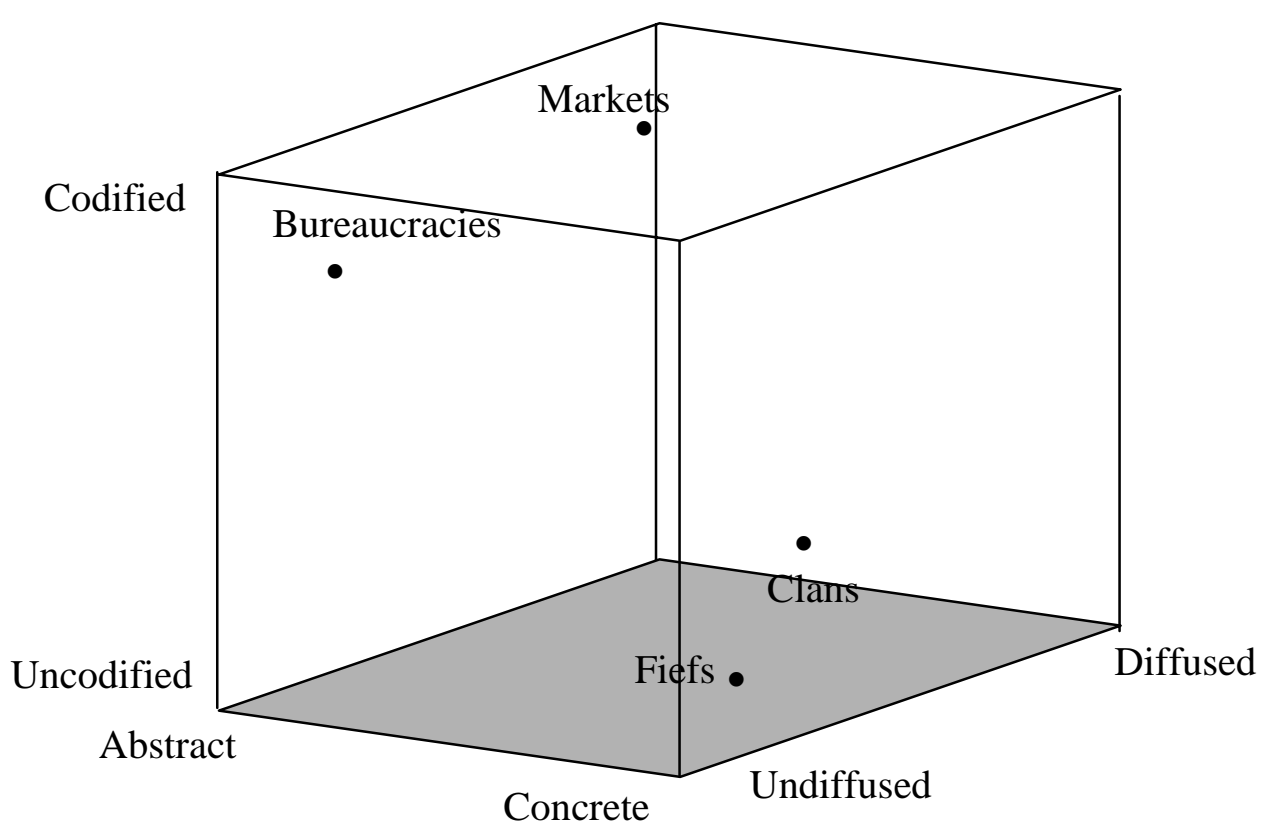

Figure 5: Institutional Structures in the I-Space 


\begin{tabular}{|c|c|}
\hline $\begin{array}{l}\text { BUREAUCRACIES } \\
\text { - Information diffusion limited and under } \\
\text { - } \text { central control } \\
\text { - } \text { helationships impersonal and } \\
\text { - Submission to superordinate goals } \\
\text { - Hierarchical coordination } \\
\text { - } \quad \text { No necessity to share values and beliefs }\end{array}$ & $\begin{array}{l}\text { MARKETS } \\
\text { - Information widely diffused, no control } \\
\text { - } \quad \text { Relationships impersonal and competitive } \\
\text { - } \quad \text { No superordinate goals - each one for himself } \\
\text { - Horizontal coordination through self- } \\
\text { - } \quad \text { Negulation } \\
\text { - No necessity to share values and beliefs }\end{array}$ \\
\hline $\begin{array}{l}\text { FIEFS } \\
\text { - Information diffusion limited by lack of } \\
\text { - } \quad \text { Redification to face-to-face relationship } \\
\text { (feudal/charismatic) } \\
\text { - Submission to superordinate goals } \\
\text { - Hierarchical coordination } \\
\text { - Nereccitv tn chare valıes and heliofc }\end{array}$ & $\begin{array}{l}\text { CLANS } \\
\text { - Information is diffused but still limited by } \\
\text { lack of codification to face-to-face } \\
\text { relationships } \\
\text { - Relationships personal but nonhierarchical } \\
\text { - Goals are shared through a process of } \\
\text { negotiation } \\
\text { - Horizontal coordination through negotiation } \\
\text { - Necessitv to share values and heliefs }\end{array}$ \\
\hline
\end{tabular}

Table 1: Characteristics of Institutional Structure 


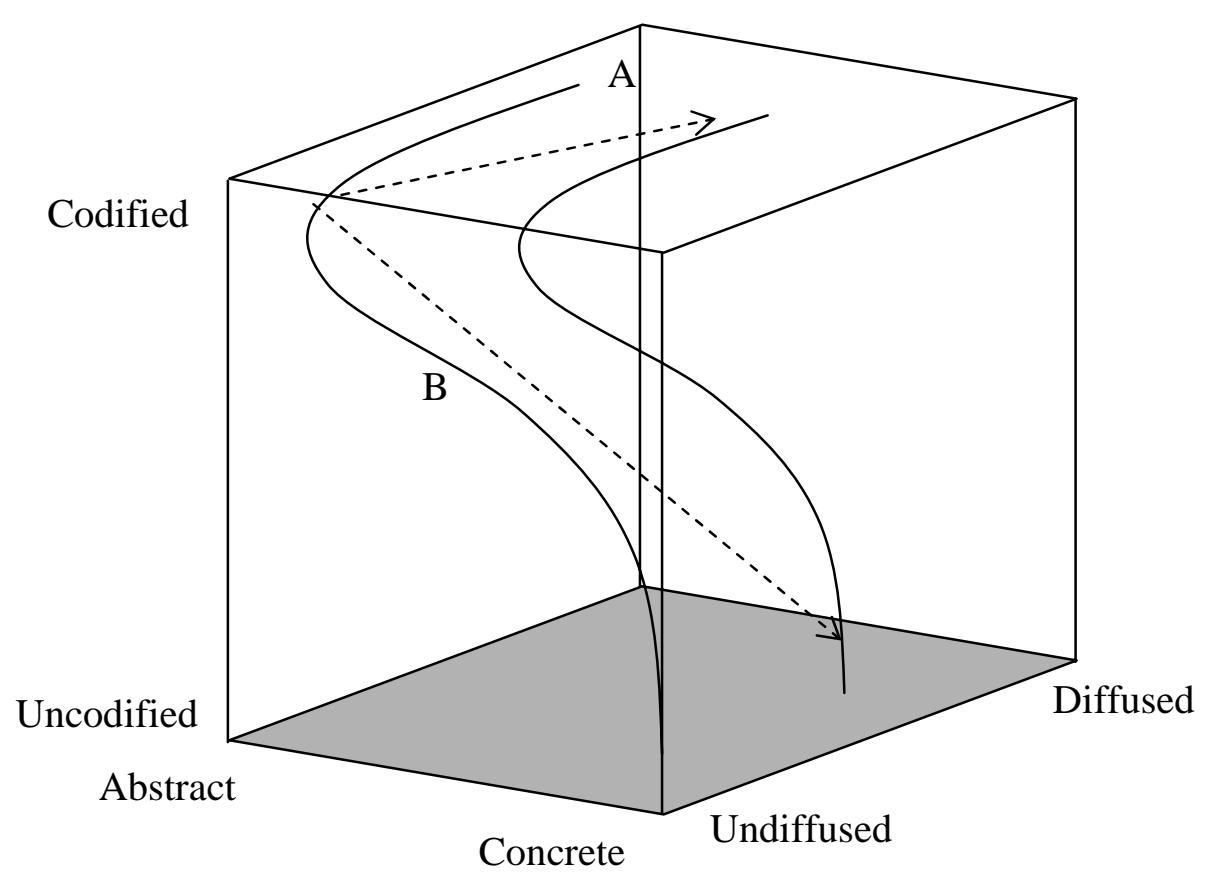

Figure 6: The Impact of ICTs in the I-Space 